\title{
SUPERNUMERARY CHAMBERS TO THE LEFT HEART
}

\author{
BY \\ P. J. BARNARD AND A. J. BRINK \\ From the Departments of Pathology and Internal Medicine (Cardiac Unit of South African Council for Scientific \\ and Industrial Research), University of Pretoria
}

Received August 2, 1955

Unique abnormalities were found in the hearts of two patients who recently came to necropsy. A supernumerary left atrium was present in each and communicated with the left ventricle by means of an ostium distinct from the mitral valve. In one of these hearts there was an additional miniature ventricle on the left, and in the other there was possibly a rudimentary extra ventricle. The clinical findings in one of these patients were distinctive enough to have made clinical diagnosis possible. In each instance the anomaly contributed directly to the patient's cardiac difficulties.

\section{CASE REPORTS}

Case 1. Accessory left-sided two-chambered heart (Bantu girl, aged 5 years).

Shortness of breath had been noticed since birth, but the child had apparently developed normally. Three weeks before admission she began to cough spasmodically, becoming very dyspnœic and blue, and occasionally vomiting.

On examination, abnormalities were confined to the cardiovascular system and the lungs. She was short of breath at rest, but there was no cyanosis, no abnormal venous pulsation, no distension of the neck veins, nor any other signs of failure. Numerous moist crepitations were scattered through both lung fields. The blood pressure was $100 / 68 \mathrm{~mm}$. $\mathrm{Hg}$ and the pulse rate $130 \mathrm{a}$ minute. The heart was enlarged and the apex beat had a left ventricular quality impulse, maximal in the anterior axillary line. A grade III systolic murmur was conducted round toward the axilla to the left. A blowing diastolic murmur, quite unlike the rumble of mitral stenosis, was localized to the mitral area. The first mitral sound was not accentuated. There were no murmurs at the base of the heart and the second pulmonic sound was normal.

The heart was enlarged and there was much prominence in the region of the left auricular appendage and in the posterior-anterior view (Fig. 1). This shadow could not be separated from the rest of the atrial shadow on rotating into the oblique positions, and appeared to be attached to the left atrial appendage and pulsated actively and in time with the pulmonary artery and aorta. In oblique views the cardiac enlargement appeared to be due to enlargement of the left ventricle. The barium-filled œsophagus showed no left atrial enlargement.

The electrocardiogram showed sinus rhythm with a $\mathrm{P}-\mathrm{R}$ interval of $0 \cdot 12 \mathrm{sec}$. It showed a normal axis and a vertical heart position. The $S$ wave of $20 \mathrm{~mm}$. in V1 with a predominant $R$ wave of $7 \mathrm{~mm}$. in V6 and slight S-T depression in V4, V5, and V6 were evidence of left ventricular hypertrophy. There was some $\mathrm{T}$ inversion in V1-V3 but in a child of this age this was thought to be normal.

The urine contained a trace of albumin. The hæmoglobin was 80 per cent $(11.9 \mathrm{~g}$. per $100 \mathrm{ml}$.); the red blood cells, 4,620,000, per c.mm.; and the white blood cells, 27,000 per c.mm. with a neutrophilic predominance. The Kolmer and Khan tests were negative.

During the patient's stay in hospital she had a temperature of $99^{\circ}-101^{\circ} \mathrm{F}$. She was treated with antibiotics and digitalized. There was no improvement, however, and she gradually declined and died three weeks after admission.

Necropsy findings. There was no dependent œdema or transudate within the serous cavities. A small caseous, partially calcified lymph node occupied the left lung hilus. No Ghon focus or other abnormality was discovered in the lungs. All organs except the heart were normal and there were no signs of passive venous congestion. 


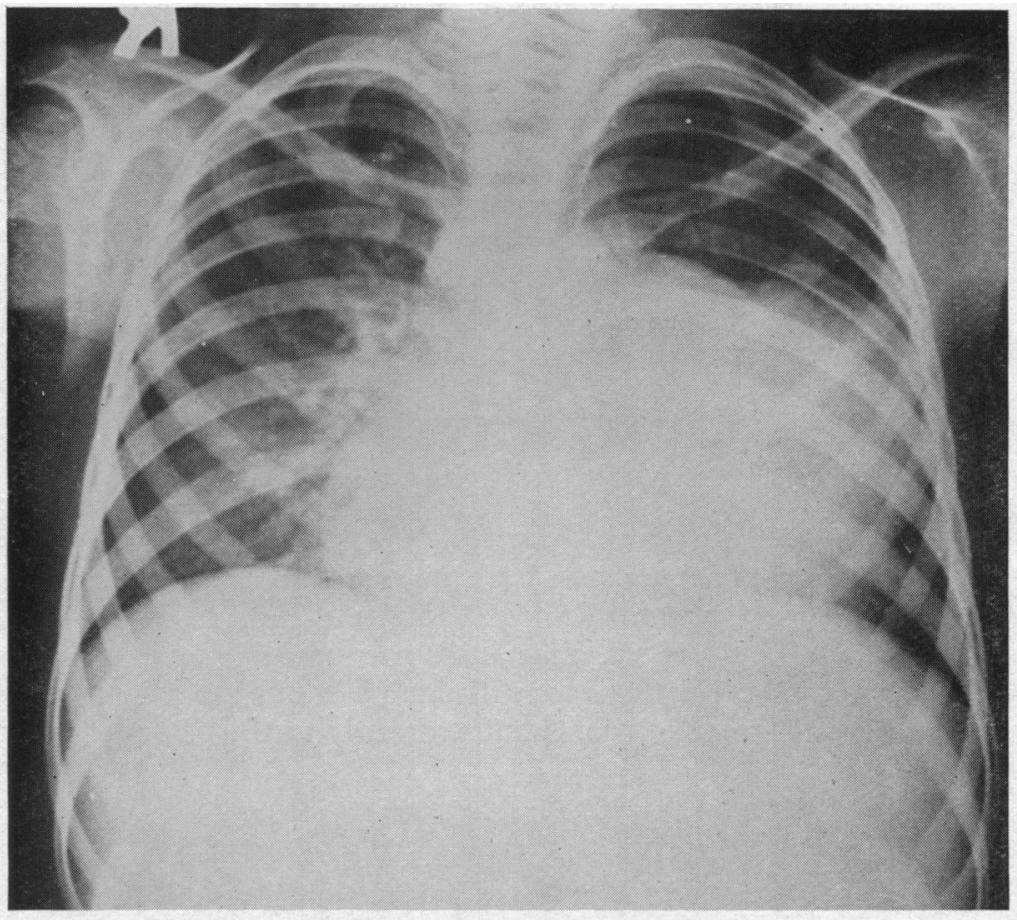

FIG. 1.-Posterior-anterior film of chest, illustrating prominence in region of the left atrial appendage. Case 1.

The heart weighed $170 \mathrm{~g}$. (normal $90 \mathrm{~g}$.). This normal weight and the values given for thicknesses of cardiac chambers, as well as normal measurements of valvular circumferences have been taken from the tables set out by Gould (1953). The most striking feature of this heart was a large sac lying to the left of the left atrium (Fig. 2). The pericardium was adherent over the entire heart, including the sac.

The right atrium was normal, its wall averaging $1 \mathrm{~mm}$. in thickness. The coronary sinus and great veins entered normally. The tricuspid valve was properly formed and was attached by normal chordæ to anterior, posterior and conus papillary muscles.

Both conus and body of the right ventricle had undergone hypertrophy. The mean thickness was $3 \mathrm{~mm}$., which equalled that of the normal adult ventricle (2-3 mm.). Dilatation had taken place because the right $\mathrm{A}-\mathrm{V}$ ring was $9 \mathrm{~cm}$. in circumference, a figure close to those recorded for adult women. The pulmonic valve was normal and measured $4.5 \mathrm{~cm}$. in circumference. Immediately beyond it the pulmonary trunk was $4.8 \mathrm{~cm}$. in circumference. Neither the trunk nor its main branches were dilated or involved by arteriosclerosis.

The left atrium was 1-2 mm. thick (normal 1-2 mm.). Its wall was united with the adjacent sac wall by adhesions only. Pulmonary veins of normal calibre entered at the usual sites. The mitral valve, its chordæ, and their attachments to papillary muscles were normal, except that the mitral ring at its lateral edge was not united with myocardium for a distance of $1 \mathrm{~cm}$. Immediately lateral to this free part, but medial to the left ventricular wall, was situated an oval ringed aperture, $3 \mathrm{~cm}$. in circumference, which gave access to the sac (Fig. 4). The left ventricular wall was hypertrophied, measuring $7 \mathrm{~mm}$. (normal adult 8-10 mm.) and dilated, since the circumference of the mitral ring was $9 \mathrm{~cm}$. equalling that for adult women. The circumference of the aortic valve was $4.5 \mathrm{~cm}$., and that of aorta itself immediately above $5.5 \mathrm{~cm}$. The aortic valve and aorta were normal, and the ductus arteriosus had been obliterated.

The sac (Fig. 2 and 3) was bilocular and consisted of a large, thin-walled upper compartment and a small, thick-walled lower compartment. The upper compartment was $8 \mathrm{~cm}$. long, $6 \mathrm{~cm}$. wide and $6 \mathrm{~cm}$. from front to back. Corresponding figures for the lower compartment were 3,3 , and $4 \mathrm{~cm}$. These compartments were marked off from one another on the outside and in front by the A-V sulcus of the heart. 


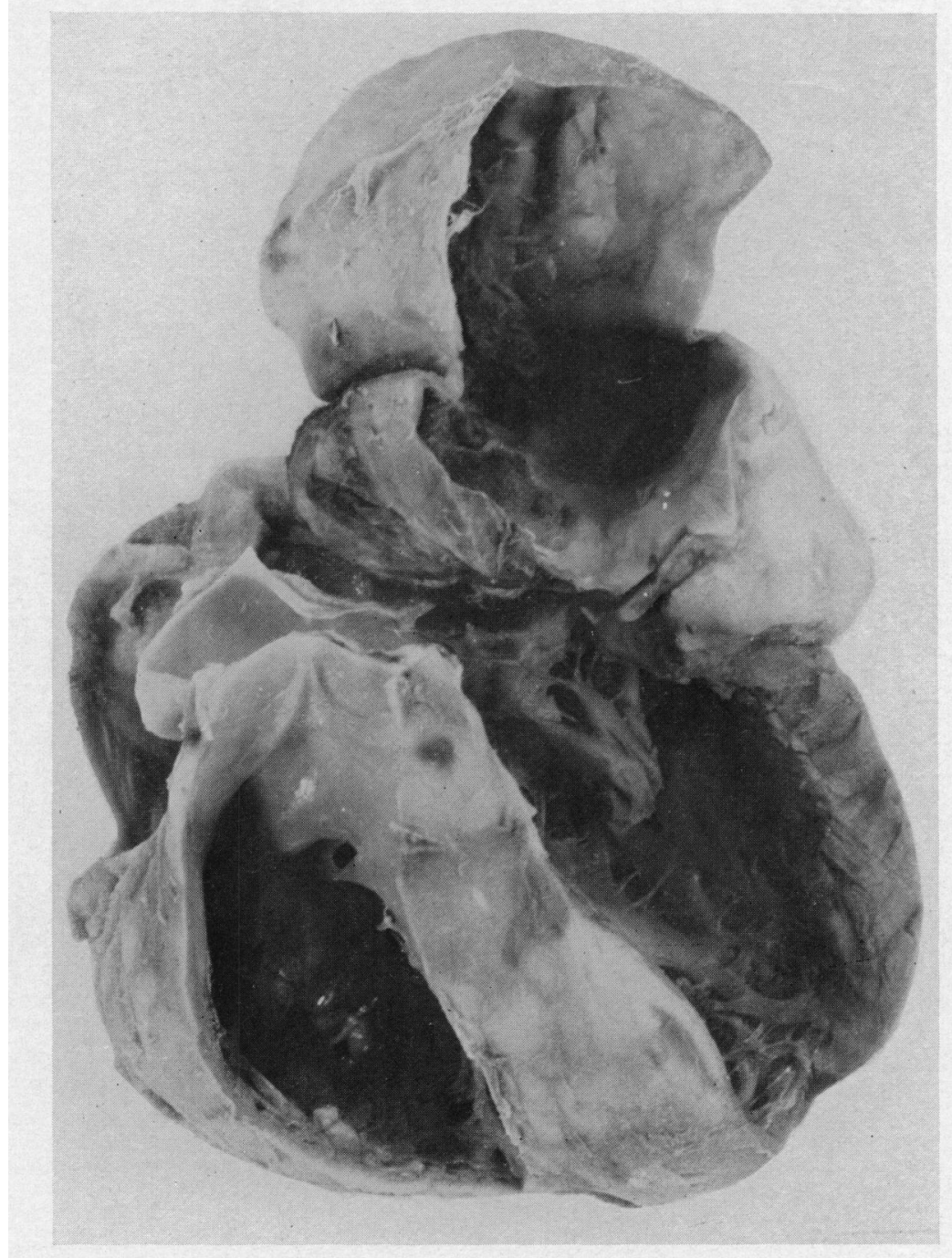

FIG. 2.-The four-chambered heart and the left-sided two-chambered accessory heart. The anterior walls of the sac and the ventricles have been cut away. Upper and lower compartments of the two-chambered heart are delimited by the atrio-ventricular sulcus of the four-chambered organ. (Stitches in the posterior sac wall close the site where tissue was taken for microscopical examination.) Case 1.

The upper compartment was thin, $1 \mathrm{~mm}$. in its upper two-thirds, but elsewhere it measured $2 \mathrm{~mm}$. Medially and posteriorly two pockets occupied by patches of fibrinous deposit were present. The endocardium was everywhere dull and opaque. This compartment neither received nor gave off any vessels. It communicated inferiorly with the lower compartment by a circular orifice possessing a smooth, firm edge (Fig. 2). This orifice was $4.3 \mathrm{~cm}$. in circumference and was situated at the level of the A-V sulcus. The lower compartment was pyriform in shape, was $5 \mathrm{~mm}$. thick and walled by myocardium. Inside it three thick cones of cardiac muscle passed medially from its anterior, lateral and posterior walls. Inferiorly, this lower compartment communicated with the left ventricle by means of an oval orifice $4.3 \mathrm{~cm}$. in circumference (Fig. 3). Its medial half was formed by the free part of the mitral ring, its lateral half by tapering ring tissue that blended with locally thickened ventricular endocardium.

The origin and distribution of the coronary arteries were normal. The circumflex branch of the left 
coronary was the chief source of arterial blood for both compartments. Venous drainage was of normal pattern, the sac walls emptying by small radicles into the coronary sinus.

Microscopically, the left atrial endocardium was slightly thickened by fibrous connective tissue. Thin strands of cardiac muscle embedded in dense collagen formed the wall of the upper compartment of the sac which was lined by fibrosed endocardium and, in places, by organizing fibrin as well. The lower compartment consisted of normal myocardium with an outer investment of fibrosed epicardium. Small arteries within the sac wall were narrowed by endarteritis fibrosa, but in the heart itself the coronary arteries were normal. The lungs were congested only in those places where early bronchopneumonia had developed; alveolar spaces in these pneumonic areas, but not elsewhere, contained hæmosiderin laden macrophages. The alveolar walls themselves were normal. Intra-pulmonary arteries of 0.1 to $1.0 \mathrm{~mm}$. external diameter were mildly involved by endarteritis fibrosa. Neither these muscular arteries nor elastic arteries of external diameter greater than $1.0 \mathrm{~mm}$. were atheromatous or hypertrophied. The pulmonary veins were normal. Precapillary vessels (which are large calibre endothelial tubes resting on an elastic lamina of diminishing completeness depending upon size) were involved by transformation of the endothelium into collagen or a substance reacting only pale pink to van Gieson's stain. It was thought unlikely that these precapillary changes had of themselves been sufficient, by causing obstruction, to have produced right ventricular hypertrophy. Though spleen and kidneys were congested, this might as well have been due to active hyperæmia from the bronchopneumonia as to right heart failure. 
Case 2. Bipartite left atrium consisting of right and left compartments and rudimentary left ventricular tissue (Bantu man, aged 26 years).

This patient worked as a despatch clerk in a store and was apparently quite well until three months before admission. He then began to complain of shortness of breath which appeared episodically both night and day and increased in severity and persistence so that he was soon unable to walk even a few steps. During this time he noticed swelling of the legs and abdominal distension. For one month he had coughed continuously. There were no other significant features in this patient's history, apart from the belief that he had had rheumatic fever at the age of 15 years.

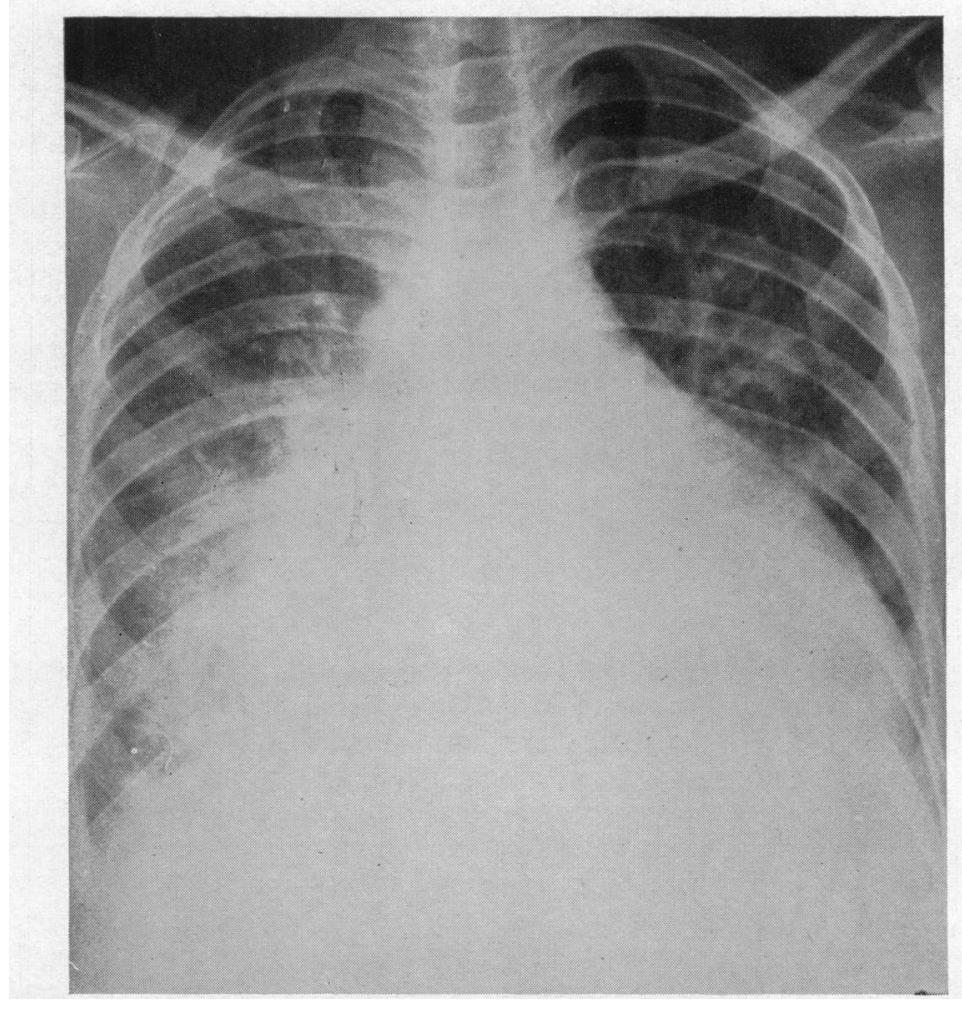

FIG. 4.-Posterior-anterior film of chest, illustrating generalized cardiac enlargement and pulmonary congestion. Case 2.

On examination he was acutely ill and orthopnœic. There was œdema of the whole body, especially the legs, and the abdomen was distended with free fluid. The heart rate was 110 a minute. The blood pressure was $130 / 100 \mathrm{~mm}$. $\mathrm{Hg}$ and the extremities felt cold. The heart had a diffuse impulse maximal outside the mid-clavicular line. A systolic thrill was palpable and a harsh, systolic murmur was heard over the mitral area, conducted well round to the axilla. A late diastolic murmur with a crescendo quality was heard at the mitral area, and a third heart sound at the apex. The second pulmonic sound was accentuated.

There was generalized cardiac enlargement (Fig. 4) which appeared in the oblique views to involve both left and right ventricles. There was no evidence of left atrial enlargement. Both lung fields were much congested. The electrocardiogram (Fig. 5) showed a vertical heart position with right axis deviation. The $T$ waves were negative in leads V3-V6. These findings were attributed to left ventricular hypertrophy.

The urine showed no abnormalities. The hæmoglobin was 90 per cent $(13.4 \mathrm{~g}$. per $100 \mathrm{ml}$.). The white blood cells were normal with a neutrophilic preponderance. The blood urea was $61 \mathrm{mg}$. per $100 \mathrm{ml}$. Serological tests for syphilis were negative.

The patient received intensive treatment with digitalis and diuretics, but his condition deteriorated and he died in congestive cardiac failure after six weeks in hospital. 


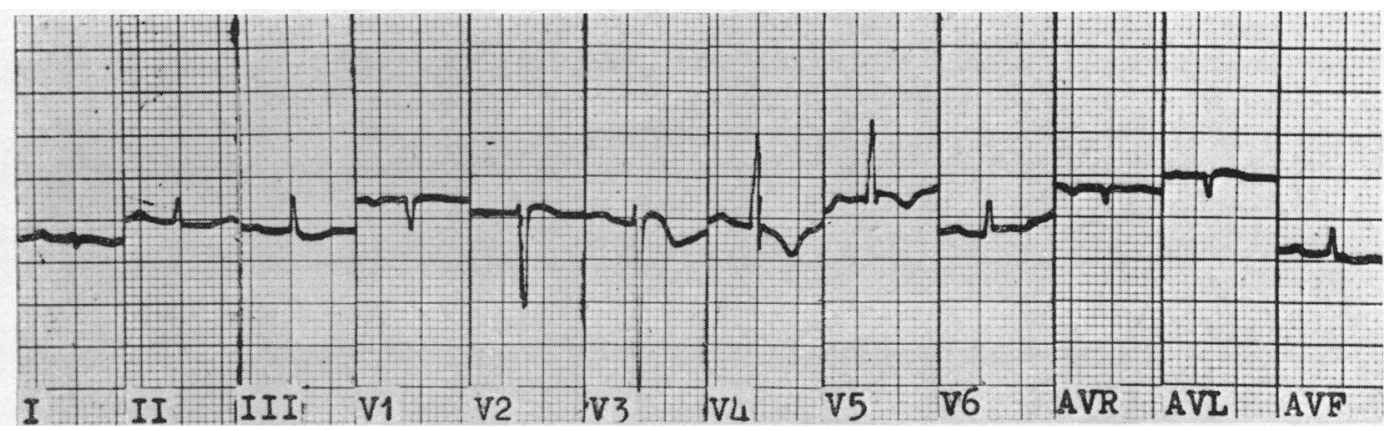

FIG. 5.-Electrocardiogram, showing the features that were interpreted as left ventricular hypertrophy. Case 2.

Necropsy findings. Severe dependent œdema, ascites (3 litres), bilateral hydrothorax (1 litre in each pleural cavity), and hydropericardium $(500 \mathrm{ml}$.). The liver was passively congested and transected by a few coarse bands of fibrous tissue. A number of old infarcts were present in the kidneys. The lungs and abdominal viscera were passively congested.

The heart weighed $470 \mathrm{~g}$. (normal, $312 \mathrm{~g}$.). Its most arresting feature was a large sac situated beside the left atrium (Fig. 6). The sac turned out to be a dilated left compartment of the left atrium, this chamber having been partitioned into two by an incomplete, vertically directed septum.

The right atrium was dilated, its wall measuring $2 \mathrm{~mm}$. in thickness (normal, 1-2 mm.). The coronary sinus and great veins entered the right atrium normally. The right atrial appendage was free from antemortem thrombus and the foramen ovale was closed. The tricuspid valve, $15 \mathrm{~cm}$. in circumference (normal, $12 \mathrm{~cm}$.) was intact and attached by normal chordæ to anterior and posterior papillary muscles and directly to the crista supra-ventricularis, the conus papillary muscle not having developed. A well-marked moderator band was present.

The right ventricle was greatly hypertrophied and dilated, its wall measuring $6 \mathrm{~mm}$. in mean thickness (normal, 2-3 mm.). The pulmonary valve was $8 \mathrm{~cm}$. in circumference (normal, $8.5 \mathrm{~cm}$.) and free from pathological change. The right ventricular endocardium was not thickened. Immediately beyond the valve, the pulmonary arterial trunk was $8.5 \mathrm{~cm}$. in circumference (normal, 7-9 cm., Parkinson, cited by Brenner, 1935); its extrapulmonary branches were not obviously dilated. A small, fibrous intimal plaque, $1 \mathrm{~cm}$. in diameter, was found in the anterior wall of the trunk $3 \mathrm{~cm}$. above the pulmonary valve. This plaque was regarded as a jet lesion. Elsewhere both trunk and its extrapulmonary branches were free from arteriosclerosis.

The right compartment of the left atrium was dilated and measured $3 \mathrm{~mm}$. in thickness (normal, $1-2 \mathrm{~mm}$.). Its appendage resembled a small, elongated aneurysm, $4 \mathrm{~cm}$. long, which communicated with the parent chamber by a circular orifice only a little less in size than its own circumference, which was $8.5 \mathrm{~cm}$. The pulmonary veins were dilated and entered the right compartment of the left atrium normally. This chamber was separated from the sac to its left (left compartment) by a vertical septum provided with an oval aperture. This septum showed no trace of either a fossa ovalis or of a valvula foraminis ovalis. The endocardium of the right compartment of the left atrium was not thickened except on its posterior wall. The right compartment opened by means of a mitral valve into an hypertrophied, dilated left ventricle, $12 \mathrm{~mm}$. thick (normal, $8-10 \mathrm{~mm}$.). The interventricular septum was intact.

The cusps of the mitral valve, consisting of normally formed anterior and posterior leaflets, were attached to the mitral valve ring around its circumference. The leaflets themselves were covered on both atrial and ventricular aspects by thickened endocardium. The left ventricular endocardium was otherwise normal. Chordæ which were not thickened or shortened, were attached normally to the valve and to anterior and posterior papillary nuscles. The mitral ring, $10 \mathrm{~cm}$. in circumference (normal, $10 \mathrm{~cm}$.) was entirely free from myocardial attachment in its lateral half: this free half was represented by a smooth, slightly flattened cord, $2 \mathrm{~mm}$. thick, to which was joined superiorly along its entire free extent, a distance of $5 \mathrm{~cm}$., the septum that had incompletely partitioned the left atrium into two compartments. The circumference of the aortic valve was $7 \cdot 5 \mathrm{~cm}$. (normal, 7-8 cm., Parkinson, cited by Brenner, 1935).

The sac (left compartment of the left atrium) was $5.5 \mathrm{~cm}$. long, $5 \mathrm{~cm}$. wide and $6 \mathrm{~cm}$. from front to back. It was lined throughout by thickened endocardium on which small flecks of fibrinous deposit were present low down on the posterior wall: it neither received nor gave off any vessels. The wall was $1-3 \mathrm{~mm}$. thick. 


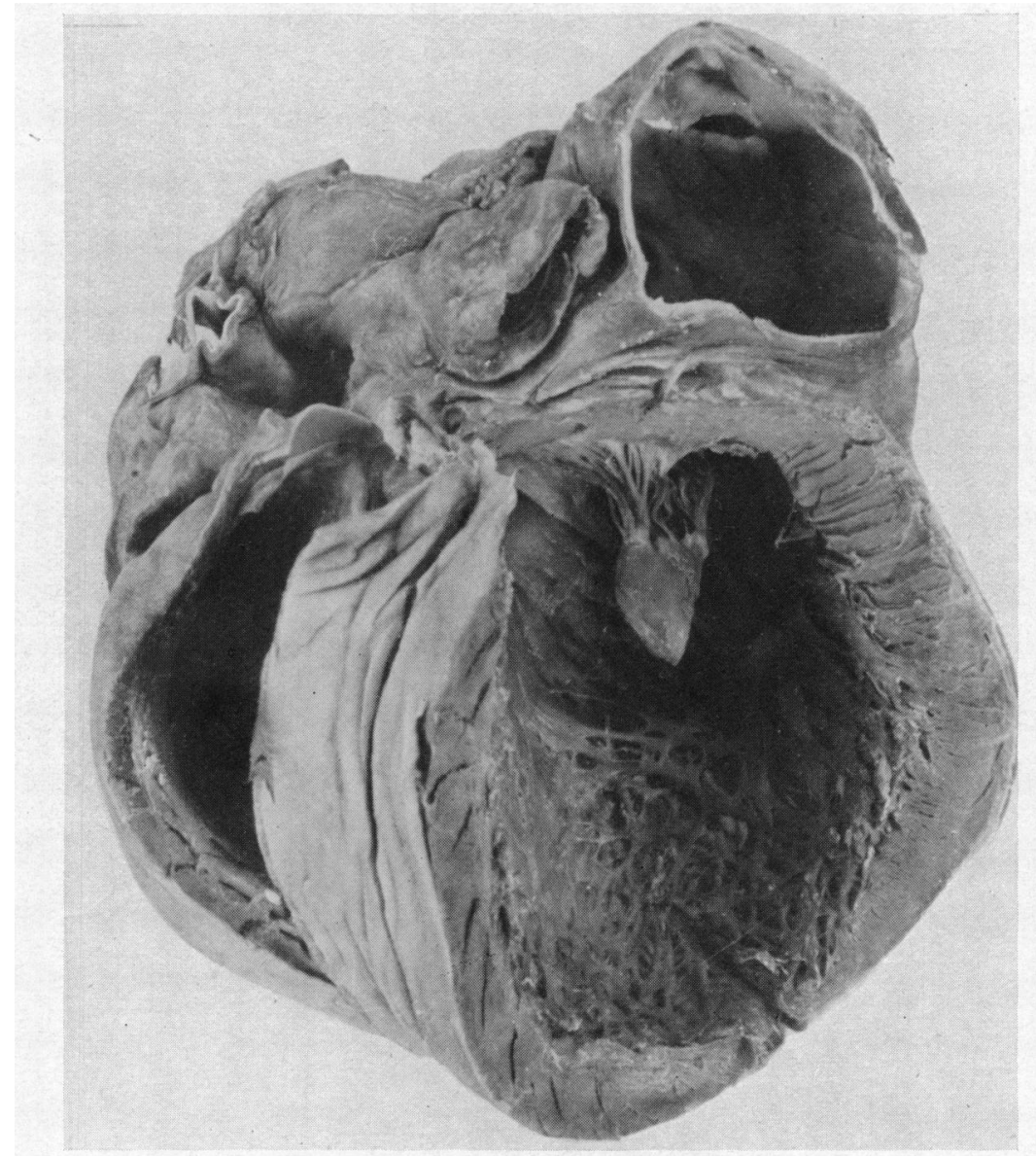

FIG. 6.- Heart with the left ventricle largely cut away, showing the dilated left atrial appendage and the sac buttressed by a pyriform mass of myocardium. The small slit situated superiorly in the sac was made for histological purposes. Case 2 .

This sac was provided with two openings, one medial and one inferior. The medial opening was placed in the septum separating sac and left atrium (Fig. 7); it was oval, measuring $2.7 \mathrm{~cm}$. in greatest length and $0.8 \mathrm{~cm}$. in greatest width. Inferiorly, this vertically directed oval aperture stopped $0.5 \mathrm{~cm}$. short of the mitral ring in its free portion, and superiorly, it fell about $3 \mathrm{~cm}$. short of the sac's summit. The edges of the opening were roughened in places by fibrinous tags. No chordæ gained attachment to what otherwise looked rather like a bicuspid valve with a small anterior and a large posterior leaflet. This medial opening occupied about one-third of the septal area. The inferior opening (Fig. 8) led out of the sac into the left ventricle. When measured with the free part of the mitral valve ring displaced maximally at the right, it was $10 \mathrm{~cm}$. in circumference, and oval in shape. Its medial half was formed entirely by the loose part of the mitral ring and its lateral half by a rim of thickened endocardium marking the point of junction between the sac and left ventricle. At this site no fibrous ring tissue could be identified. The inferior opening was not guarded by a valve, nor were any chordæ attached anywhere close to its margins. The pyriform buttress at the infero-lateral part of the sac (marked $\mathrm{A}$ in Fig. 8) consisted of solid myocardium. Fig. 8 illustrates diagrammatically the main anatomical features of this heart.

The aortic intima was slightly flecked by atheroma. The ductus arteriosus had been obliterated. The origin and distribution of the coronary arteries was normal, and they were free from atheroma. The circumflex branch of the left coronary artery was displaced downwards by the sac which received blood mainly from this vessel. Venous drainage of the heart was normal except that the sac was drained by a 


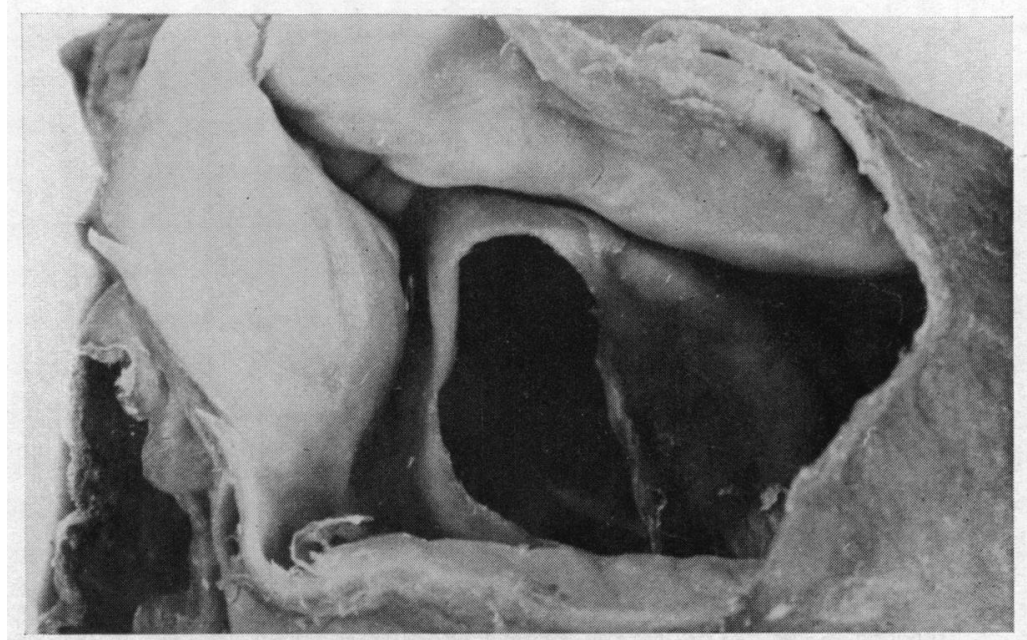

Fig. 7.-Sac with wall largely cut away to show the opening in the vertical septum that divided the left atrium into two compartments. Case 2.

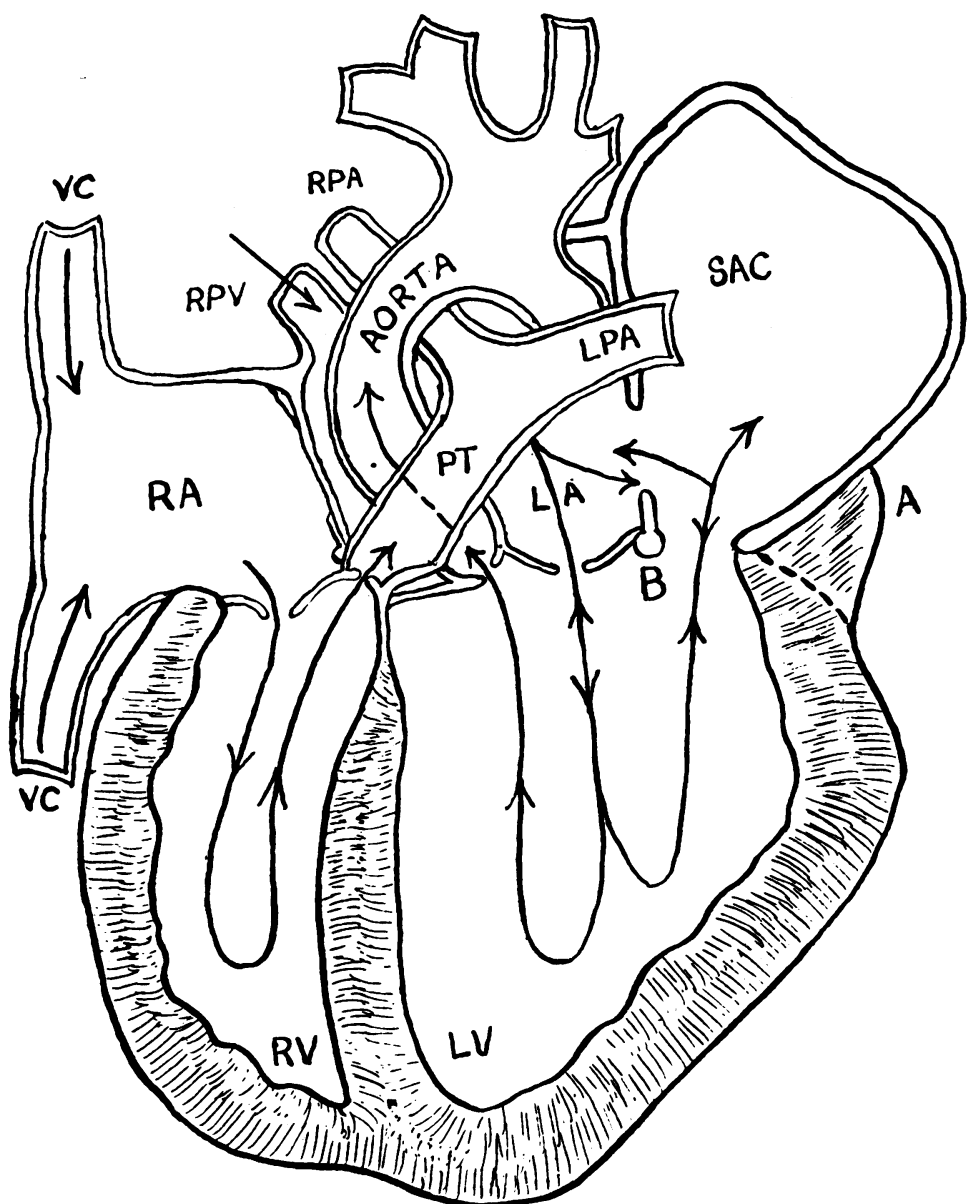

FIG. 8.-Diagram illustrating relationship between the sac (left compartment of left atrium) and rest of the heart. A is a solid myocardial buttress supporting the sac and $B$ the mitral ring in its lateral free mobile part. Case 2. 
large vein posteriorly. This vein, at its point of confluence with the coronary sinus, was marked by a fibrous intimal plaque. The pericardium was firmly adherent only over the sac and the left atrial appendage. Elsewhere it contained $150 \mathrm{ml}$. of clear fluid.

On histological examination, the presence of passive venous congestion in both greater and lesser circulations was confirmed. In the lungs there was severe intimal fibrosis involving veins and precapillary sclerosis. Arterial changes were slight, only elastic arteries being affected to any noteworthy extent by endarteritis fibrosa. Atheroma was not encountered. Sections of the liver revealed, apart from passive congestion, a few coarse fibrous trabeculæ not associated with any other abnormality. Their cause was thus obscure, but a healed massive necrosis was thought to be the probable explanation. The renal infarcts were interpreted as depending upon former thrombo-embolism originating in the sac, for here the only antemortem thrombi were found. Renal arteries, as well as pulmonary arteries, showed no more arteriosclerosis than could be attributed to chance, as comparison with controls of the same age, sex, and race showed no material differences. Sections of the heart showed endocardial fibrosis, and in places some elastosis as well, confined to the left atrium, mitral valve, and the sac wall. The sac wall in places consisted only of dense collagen lined by fibrosed endocardium, but its main component was strands of normal cardiac muscle. Similar strands were also to be found in the septum between sac and left atrium. No significant arteriosclerosis was encountered in intramyocardial branches of the coronary arteries, except for densely fibrous portions of the sac where endarteritis fibrosa was present.

\section{DisCUSSION}

No reports of cases like those here described could be found. They are distinct from cor triatriatum, a condition characterized by horizontal partition of the left atrium into upper and lower compartments (Faber, 1934; Loeffler, 1949; Parsons, 1950; and Edwards, 1951). Cases of this anomaly, as well as division of the left atrium by a vertically directed partition or septum secundum, have been summarized by Lev (1953). Atrial anomalies due to partition of the left atrium into right and left compartments by a perforated extra septum display several variations. In the first variety the right compartment of the left atrium receives the pulmonary veins. In the second the pulmonary veins enter the left compartment, the superior vena cava the right compartment, and the inferior vena cava the right atrium. In the third variety the pulmonary veins drain into the left compartment, a left superior vena cava and the coronary sinus into the right compartment, and a superior vena cava and the inferior vena cava into the right atrium.

Although cases of a double mitral orifice are also known to occur and have been reviewed in a paper by Schraft (1950), they do not appear to have been described in association with a supernumerary left atrial chamber. Duplication of the mitral orifice is described as consisting of two orifices equal or unequal in size that present in anteroposterior or lateral relationship to one another. The accessory orifice usually lies in the anterior mitral leaflet which thus has two leaflets of its own joined to the anterior papillary muscle. On the other hand, each orifice may have one leaflet with the two orifices connected by a fibrous tissue bridge. The chordæ and leaflets have all been thickened but the valves have usually been competent. A double mitral orifice may also be displaced downward into the left ventricle. In the cases reported here, the accessory orifice had none of the features described in duplication of the mitral orifice, because in each of them it was an unguarded orifice lying lateral to the mitral ring. Cases with accessory ventricles, as anomalies distinct from ventricular diverticula, have also been placed on record, but they have not had accessory atria as well (Hemsath, 1936; Konwaler, 1944).

In Case 1 the true diagnosis could have been arrived at clinically. The radiological features suggested an outpouching in the region of the left atrial appendage, and the position of this shadow and its active pulsations related it to the cardiac chambers. Moreover, the pulsations had a paradoxical excursion showing lively expansion with each ventricular systole. This was interpreted as a mitral incompetence allowing distension of an atrial aneurysm during ventricular systole. It was difficult to explain the diastolic blowing murmur localized to the mitral area, but in retrospect this was apparently due to the diastolic emptying of the accessory sac into the left ventricle, and had the significance of this been grasped, one might have made an accurate diagnosis of an accessory atrial sac with an unguarded orifice leading into the left ventricle. 
In Case 2 congestive cardiac failure together with a systolic murmur in the mitral area conducted round to the back, and the presence of a large left ventricle indicated mitral incompetence. Indeed, this patient's mitral valve was grossly incompetent at necropsy, and the diagnosis was only wrong in so far as the cause of the incompetence was not rheumatic, but detachment of the mitral ring. In neither case was the electrocardiogram sufficiently distinctive to diagnose anything more than left ventricular hypertrophy.

The bilocular sac described in Case 1 was regarded as an accessory two-chambered heart, for the following reasons. Cardiac muscle was present in the walls of both compartments, which were demarcated from one another by the A-V sulcus of the heart itself. This sulcus was occupied by the circumflex branch of the left coronary artery. Also, the orifice connecting the upper and lower compartments was situated in the same plane as the A-V sulcus. There were well formed trabeculæ carneæ present inside the lower compartment. The upper compartment was joined to the left atrium only by adhesions and since they had not been united by muscle they must be regarded as anatomically distinct. Though myocardium of the lower compartment merged with that of the left ventricle, the point of junction between them consisted of loosely woven muscle separable with greater ease than were muscle trabeculæ elsewhere. No acquired lesion was found that could explain this bilocular formation, the structure of which conformed rather with the directive influence of an organizer than the chance results of an acquired disease affecting both atrium and ventricle. The endarteritic vessels supplying the sac walls were not regarded as causal because they are usually to be found in the presence of fibrous atrophy and hypoplasia.

It is suggested that abnormal development had occurred prior to midline fusion of the endocardial tubes, but subsequent to the establishment of a single pericardium as its cavity was common to both heart and accessory chambers. The endocardial tubes that had developed from the cardiac primordia, though approximated to the midline, had fused completely only at the point where the mitral valve was ultimately to develop. The right endocardial tube subsequently gave rise to the heart itself and established normal relationships with the great vessels, whereas a smaller left tube developed only into a two-chambered heart. Fusion had not taken place at all cephalad resulting in a completely separate atrium, whereas caudad, fusion had been almost complete, producing a miniature ventricle riding upon and partially merged with the left ventricle. Endocardial cushion tissue having completed the mitral ring and its valve leaflets, would seem to have undergone canalization laterally, so providing communication with the two-chambered heart. Alternatively, the endocardial tubes had fused completely, but a second left smaller tube or endocardium-lined lacuna had persisted or had formed in addition and then established the partial fusion just described. A third explanation is that the cardiac tube had formed normally but had undergone partition into two unequal parts by a double set of interatrial and interventricular septa, so forming a fourchambered and a two-chambered heart. This is improbable, because the upper compartment of the accessory heart was entirely separate, suggesting independent development, as otherwise a septum common to both the left atrium and to this compartment should have formed. This third explanation, therefore, suffers from the complexity of requiring independent origin for the accessory left atrium and a double but unequal partition of the primitive left ventricle.

The left ventricular hypertrophy and dilatation has been ascribed to mitral valve incompetence, because its ring possessed mobility and a defect at its lateral margin. Left ventricular failure, however, had not occurred, as the lungs were not passively congested. Why the right ventricle should have undergone hypertrophy is not known, but hypertrophy was attributed to pulmonary hypertension, because arteriolar and precapillary sclerosis was present in the lungs. As the extent of the vascular changes were not thought to be severe enough to have caused the right ventricular hypertrophy by obstruction alone, they have been regarded as a result and not as a cause of the pulmonary hypertension which was possibly of primary type.

The heart in Case 2 was characterized by two chief abnormalities. An accessory septum had divided the left atrium vertically but incompetently into two compartments, and in the lateral half of its circumference the mitral ring lacked attachment to left ventricular myocardium. 
It is uncertain whether this lack of attachment was congenital or acquired. Because the orifice that communicated between left ventricle and the sac had not developed a valve ring of its own, it was thought possible that the mitral ring had become stripped from the myocardium at some time after the heart had attained a definitive structure. This possibility was strengthened by the severity of the mitral incompetence which, had it been present at birth, would have led to failure before adult life. We concluded, therefore, that lateral to the mitral ring a weakness or small separation had been present and had led either to gradual stripping away of the mitral ring over a protracted time period, or to more rapid stripping shortly before death.

The accessory left atrial septum, regarded by itself, could have been another septum primum provided with an ostium secundum. This or any other view, however, must take into account the myocardial buttress (Fig. 6 and 8 ) situated below the level of the A-V sulcus. In this heart much will depend upon whether the buttress is accepted as accessory myocardium, or whether it is thought to have developed in fœtal life through displacement of primitive left ventricular myocardium by dilatation of the left atrial compartment. If this buttress were to be taken for an accessory hypoplastic ventricle, then it and the left atrial compartment might have been an accessory two-chambered heart that had arisen at the stage of endocardial tube fusion. This interpretation is strengthened by the previous case in which a larger but cavitated buttress was also present. Moreover, both cases had inferior apertures situated immediately lateral to the mitral valve ring.

It might plausibly be supposed that left and right tubes had merged in the usual way, but that they also underwent fusion with an accessory left endocardial tube or with a persistent left endocardial lacuna. Cephalad this lacuna then fused partially with that part of the cardiac tube destined to become the lateral wall of the left atrium. From this incomplete fusion resulted the opening that otherwise must be regarded as having formed in a second septum primum. Caudad, however, fusion with that part destined to form the lateral wall of the left ventricle was complete, producing only a pyriform mass of solid myocardium. At the site where the primitive left ventricle of the accessory heart had fused with the left ventricle, the mitral ring was prevented from establishing firm union with ventricular myocardium, so that finally it loosened to cause severe incompetence of the mitral valve.

\section{SUMMARY}

The clinical and pathological features in two patients with developmental cardiac anomalies have been described. These particular anomalies do not appear to have been recorded before.

The first consisted of a four-chambered heart, with which a left-sided, two-chambered heart was partially merged. In retrospect, this cardiac defect might have been diagnosed during life.

The second consisted of a four-chambered heart, the left atrium of which had been vertically but incompletely divided into two compartments. The left compartment of the bipartite left atrium was supported by a pyriform buttress of solid myocardium. The bipartite left atrium might either be considered to have arisen from the formation of an accessory septum primum, or the atrial anomaly together with its myocardial buttress might have represented a partially fused two-chambered left-sided heart.

We wish to thank Professors H. W. Snyman and J. G. Davel for permission to publish, and Mrs. P. Barnard, a stipendiary of the South African Council for Scientific and Industrial Research, for the histological and photographic work.

\section{REFERENCES}

Brenner, O. (1935). Arch. intern. Med., 56, 211.

Edwards, J. E., du Shane, J. W., Alcott, D. L., and Burchell, A. B. (1951). Arch. Path., $51,446$.

Faber, V. (1934). Centralblatt alleg. Path. path. Anat., 61, 225.

Gould, S. E. (1953). Pathology of the Heart. Charles C. Thomas. Springfield, Illinois, U.S.A.

Hemsath, F. A., Greenberg, M., and Shain, J. H. (1936). Amer. J. Dis. Children, 51, 1356.

Konwaler, B. E. (1944). Amer. Heart J., 27, 259.

Lev, M. (1953). Anomalous Septum, p. 41. Charles C. Thomas, Springfield, Illinois, U.S.A.

Loeffler, E. (1949). Arch. Path., 48, 371.

Parsons, C. G. (1950). Brit. Heart J., 12, 327.

Schraft, W. C., and Lisa, J. R. (1950). Amer. Heart J., 39, 136. 